\title{
Hellenic Beech Forests Database (Hell-Beech-DB)
}

\author{
loannis Tsirpidis, Erwin Bergmeier, Georgios Fotiatidis \& Panayotis Dimopoulos
}

\begin{abstract}
The Hellenic Beech Forests Database (GIVD ID EU-GR-007) includes relevés dominated or co-dominated by Fagus sylvatica s.l. It includes almost all published relevés from the northeast, north-central and east-central floristic regions of Greece. Ca. 50 unpublished relevés have been already entered and more than 300 new relevés are going to be entered soon. Furthermore, existing relevés from northwestern Greece are going to be entered to complete the data. Species data concern vascular plants and additionally most relevés have environmental data such as altitude, aspect, and slope inclination. For about $40 \%$ of the relevés precise geographic locality is given, while for a small proportion (ca. 3\%) soil physical and chemical attributes are included. Relevé data have already been classified into 14 vegetation units, corresponding to the association or community level. The database is available for research purposes, upon agreement.
\end{abstract}

Keywords: deciduous forest; Fagion moesiacae; Fagion sylvaticae; Fagus sylvatica.

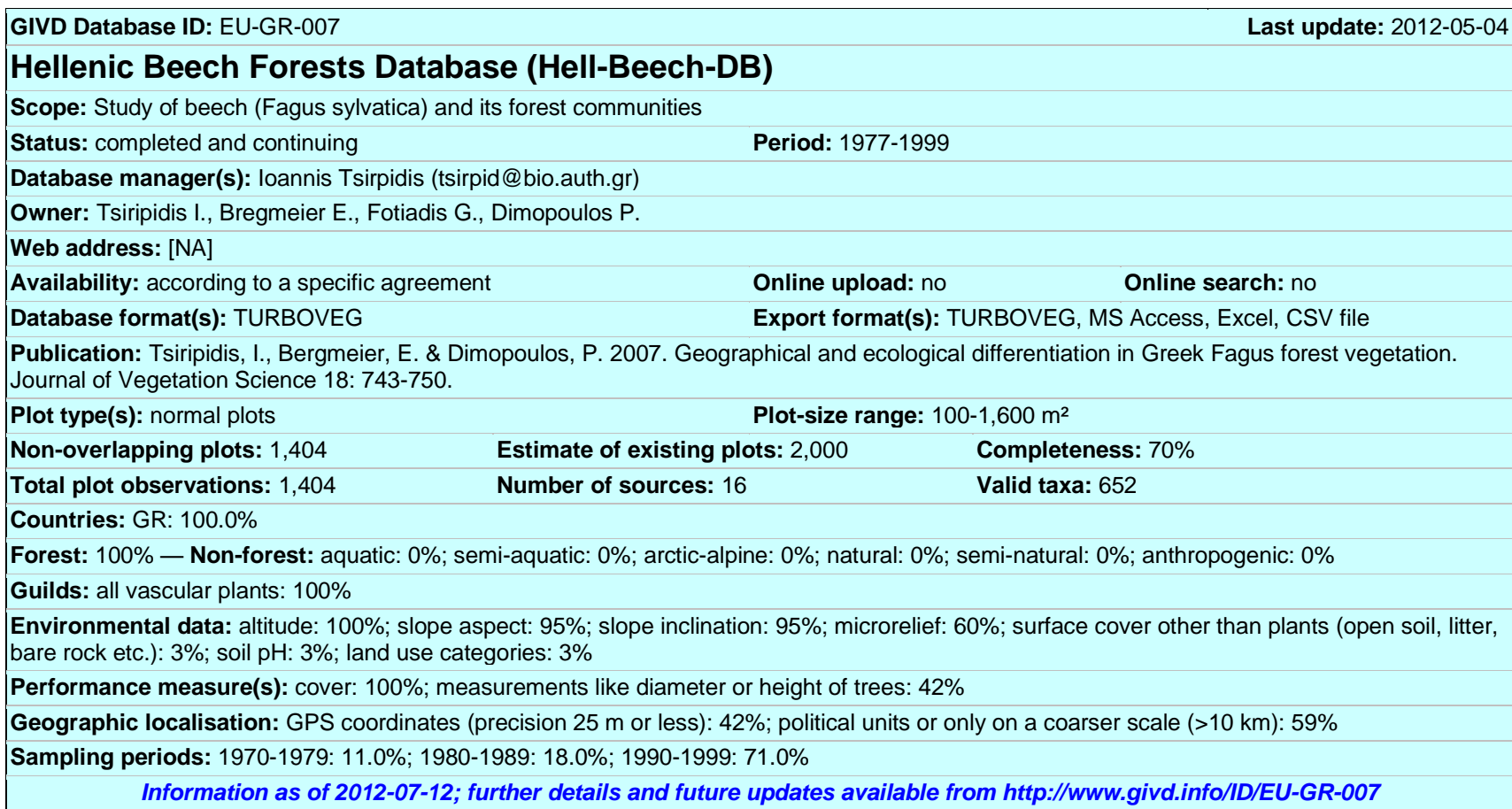

Ioannis Tsiripidis* (tsiripid@bio.auth.gr)

School of Biology, Aristotle University of Thessaloniki, GR-54124 Thessaloniki, GREECE

Erwin Bergmeier (erwin.bergmeier@bio.uni-goettingen.de)

Department of Vegetation and Phytodiversity Analysis, Albrecht von Haller Institute of Plant Sciences, University of Göttingen,

Untere Karspüle 2, DE-37073 Göttingen, GERMANY

Georgios Fotiadis (gfotiad95@gmail.com)

Department of Forestry and Management of Natural Environment, Technological Education Institute of Lamia, GR-36100 Karpenisi, GREECE

Panayotis Dimopoulos (pdimopul@uwg.gr)

Department of Environmental and Natural Resources Management, University of Western Greece, Seferi 2, GR-30100 Agrinio, GREECE

*Corresponding author 